case in a transplant recipient. Cyclophosphamide was used more often in patients without transplants than in the others ( $46 \%$ as against $5 \%$ in the first three years), and the excess was more pronounced in those who had received the drug (three cases observed as against 0.29 expected; $P<0.01$ ). Two further cases occurred in patients without transplants treated with cyclophosphamide after the latest follow-up date used for this analysis, and several other cases of bladder cancer after cyclophosphamide treatment have been reported elsewhere. ${ }^{18}$ Hence the risk of this disease is apparently related specifically to the use of cyclophosphamide.

Of other rare tumours, three were squamous carcinomas of the vulva (one in the non-transplant series), one was a metastasising carcinoid tumour (transplant series), and one was an intrahepatic biliary carcinoma (non-transplant series). The three cancers of the vulva were similar in character to squamous carcinoma of other parts of the skin and are perhaps more appropriately classed with skin cancers than with "other" cancers. The intrahepatic biliary carcinoma in a patient in the non-transplant series is interesting in view of Hoover and Fraumeni's ${ }^{8}$ report of similar cases in transplant recipients.

Our findings provide no clear evidence that immunosuppressive drugs produce an increased risk of most of the common cancers. Few of the patients, however, had been under observation for over five years, and an increase may appear later.

We are grateful to the Cancer Research Campaign for their financial support of this continuing study; to all the collaborating physicians and surgeons who have provided information about their patients; and to Cynthia Bates; Barbara Crossley; Mary Hall; Angela Hewitt; Jo Moffett; Stephanie Streat; Dr A Adelstein and the Office of
Population Censuses and Surveys; Dr J Ford of the New South Wales Cancer Registry; and Dr A J Wing, Dr N Selwood, and the European Dialysis and Transplant Association for their help in carrying out the study.

Requests for reprints should be addressed to Dr L J Kinlen.

\section{References}

1 Thomas, L, in Cellular and Humoral Aspects of the Hypersensitive States, ed H S Lawrence, p 259. London, Cassell, 1959.

2 Burnet, F M, British Medical fournal, 1965, 1, 338.

3 Penn, I, et al, Transplantation Proceedings, 1969, 1, 106.

4 Doll, R, and Kinlen, L, British Medical fournal, 1970, 4, 420.

5 Waterhouse, J A H, Cancer Handbook of Epidemiology and Prognosis. Edinburgh and London, Churchill Livingstone, 1974

${ }^{6}$ Doak, P B, et al, British Medical fournal, 1968, 4, 746.

7 Bengtsson, U, et al, Scandinavian fournal of Urology and Nephrology, $1968,2,145$.

${ }^{8}$ Hoover, R, and Fraumeni, J F, jun, Lancet, 1973, 2, 55.

${ }^{9}$ Kinlen, L J, et al. In preparation.

10 Gregory, M C, and Hughes, J T, fournal of Neurology, Neurosurgery, and Psychiatry, 1973, 36, 769 .

11 Isomaki, H A, Hakulinen, T, and Joutsenlahti, U, fournal of Chronic Diseases, 1978, 31, 691.

12 Lipsmeyer, E A, Arthritis and Rheumatism, 1972, 15, 183.

13 Uhl, G S, Williams, J E, and Arnett, F C, fournal of Rheumatology, 1974, 1,282 .

${ }^{14}$ Ulrich, J, and Wüthrich, R, European Neurology, 1974, 12, 65.

15 Walder, B K, Robertson, M R, and Jeremy, D, Lancet, 1971, 2, 1282.

${ }^{16}$ Hardie, I R, et al, Surgery. In press.

17 McCarthy, D W, Black, A L, and Milton, C W, International fournal of Cancer. In press.

18 Wall, R L, and Clausen, K P, New England fournal of Medicine, 1975, 111, 271 .

(Accepted 2 October 1979)

\title{
Effects of indomethacin on postural hypotension in Parkinsonism
}

\author{
G ABATE, R M POLIMENI, F CUCCURULlO, P PUDDU, S LENZI
}

British Medical fournal, 1979, 2, 1466-1468

\section{Summary and conclusions}

A study was conducted to evaluate the effect of indomethacin on orthostatic hypotension in Parkinsonism. Twelve elderly patients participated and the drug was given in two ways-as an intravenous infusion of $50 \mathrm{mg}$ over 30 minutes and by mouth $50 \mathrm{mg}$ thrice daily for six days. Results were assessed by measuring the degree of hypotension on standing, response to the cold pressor test, and forearm blood flow (by strain-gauge plethysmography).

Geriatric Clinic, University of Chieti, Italy

G ABATE, MD, director and professor

Medical Clinic II, University of Bologna, Italy

R M POLIMENI, MD

F CUCCURULLO,

$S$ LENZI, MD, director and professor

Department of Therapeutics, University of Bologna, Italy P PUDDU, MD, director and professor
Indomethacin significantly reduced the fall in blood pressure on standing $(P<0.001)$ and lessened or reversed orthostatic symptoms. Furthermore, there was an enhanced response to the cold pressor test and a reduction in forearm blood flow.

These findings suggest that indomethacin has a positive effect on systemic vascular resistance.

\section{Introduction}

Orthostatic hypotension is a common, disabling problem in Parkinsonism. The lesion responsible may be localised within the efferent sympathetic fibres of the baroreceptor system, ${ }^{1}$ though other lesions cannot be excluded. ${ }^{12}$ We do not know whether Parkinsonism and orthostatic hypotension constitute an incomplete or variant form of the Shy-Drager syndrome. Most workers believe that such a diagnosis requires evidence of autonomic failure (orthostatic hypotension, sexual impotence, urinary incontinence, rectal incontinence, loss of sweating, etc) in addition to the features of Parkinsonism and pyramidal or

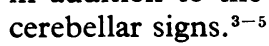

Since indomethacin proved to be effective in the Shy-Drager syndrome ${ }^{6}$ we decided to evaluate its efficacy against postural hypotension in idiopathic Parkinsonism. 


\section{Patients and methods}

We studied 12 patients: seven were men and five women, and their age range was 68-76 (mean 72) years. All showed a fall of over $25 \mathrm{~mm}$ $\mathrm{Hg}$ in mean blood pressure on standing and orthostatic symptoms (table). Mean blood pressure was calculated as (systolic blood pressure plus twice diastolic pressure)/3. ${ }^{7} \mathrm{By}$ analysis of variance orthostatic hypotension was shown to be reproducible in all patients in five different tests.

All treatment was stopped 10-15 days before the study began. The effects of indomethacin were evaluated (a) after infusing $50 \mathrm{mg}$ intravenously over 30 minutes and $(b)$ in a double-blind, randomised trial of oral indomethacin $50 \mathrm{mg}$ thrice daily and placebo conducted over six days. The following variables were measured: (a) blood pressure and heart rate in the supine and upright positions; $(b)$ blood pressure responses to the cold pressor test; and $(c)$ forearm blood flow. Blood pressure was measured by the cuff method, and forearm blood flow with a strain-gauge plethysmograph.

Values are given as means $\pm S D$. Data were analysed by a paired $t$ test.

\section{Results}

The indomethacin infusion caused an increase in supine blood pressure (systolic $141 \cdot 2 \pm 17 \cdot 7$ to $150 \cdot 8 \pm 19 \cdot 3 \mathrm{~mm} \mathrm{Hg}$; diastolic $82.5 \pm 6.6$ to $87.5 \pm 8.9 \mathrm{~mm} \mathrm{Hg}$ ) (fig 1 ); a smaller fall in mean blood pressure on standing ( $34.8 \pm 4 \cdot 1$ to $9 \cdot 3 \pm 5 \cdot 7 \mathrm{~mm} \mathrm{Hg}$ ) (fig 2); an enhanced blood pressure response to the cold pressor test $(10 \cdot 0 \pm 7 \cdot 6$ to $14.5 \pm 8.6 \mathrm{~mm} \mathrm{Hg}$ ) (fig 3); and a decrease in forearm blood flow

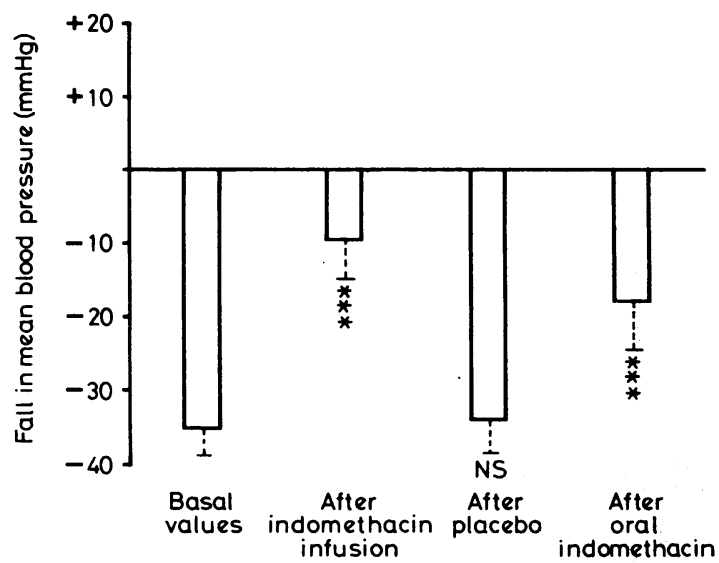

FIG 2-Effect of indomethacin and placebo on fall in mean blood pressure on standing. (Values shown $=\mathrm{SD}$.) Compared with basal value: ${ }^{* * * P}<0.001 ; \mathrm{NS}=$ Not significant.

Details of patients studied

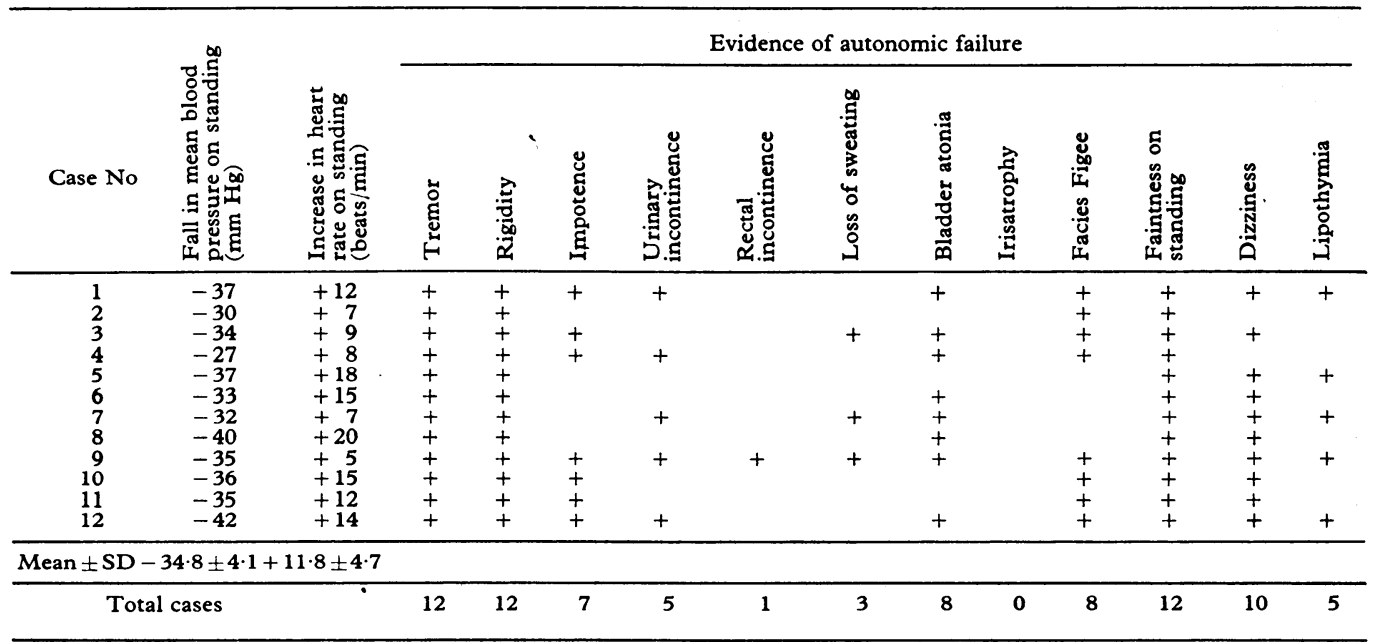

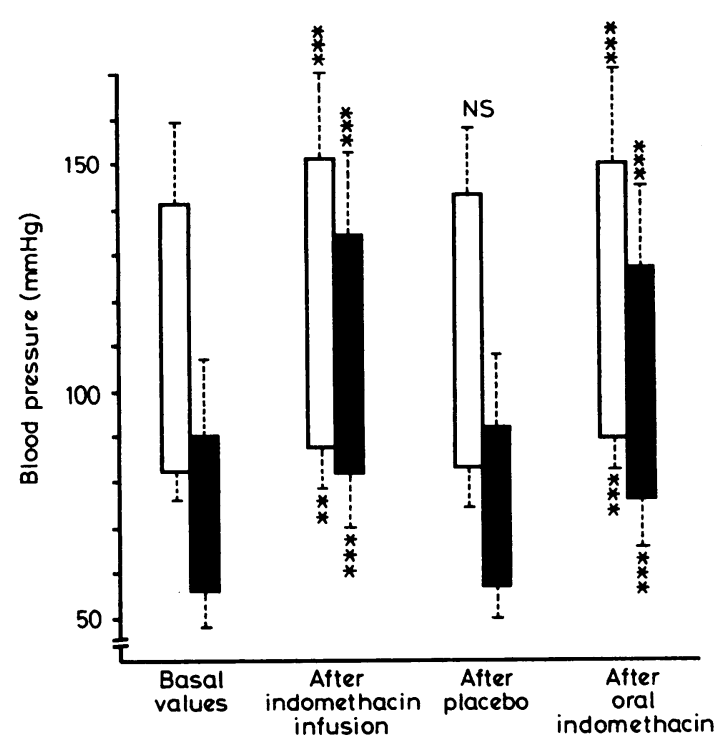

FIG 1-Mean lying ( $\square$ ) and standing ( $\square$ ) blood pressures before and after indomethacin and placebo. (Values shown $\pm S D$.) Compared with basal values: $* * P<0.005$; ${ }_{* * *} \mathrm{P}<0.001 ; \mathrm{NS}=$ Not significant

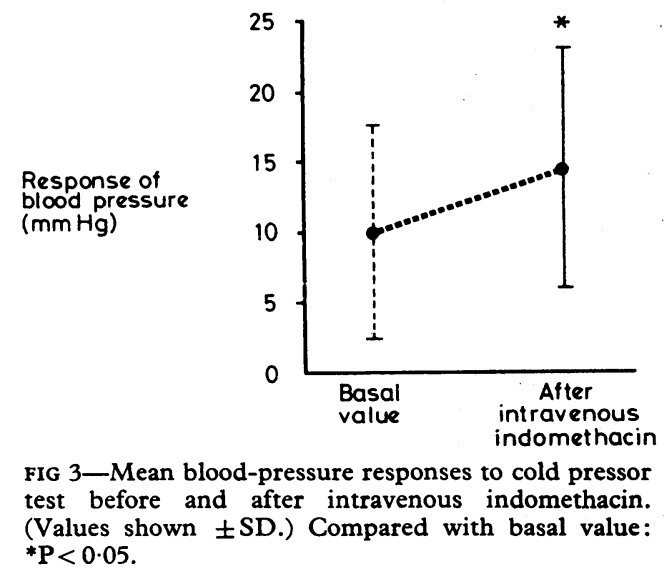

$(5.9 \pm 0.9$ to $5 \cdot 2 \pm 0.87 \mathrm{ml} / \mathrm{min} / 100 \mathrm{ml}$ ) (fig 4$)$. All these changes were statistically significant (see figs 1-4).

Oral indomethacin reduced the fall in mean blood pressure on standing (34.8 \pm 4.1 to $17.3 \pm 3.5 \mathrm{~mm} \mathrm{Hg} ; \mathrm{P}<0.001$ ), but placebo had no noticeable effect (fig 2 ).

Orthostatic symptoms were reduced or reversed by indomethacin, and in no case did indomethacin modify or aggravate Parkinsonism. 


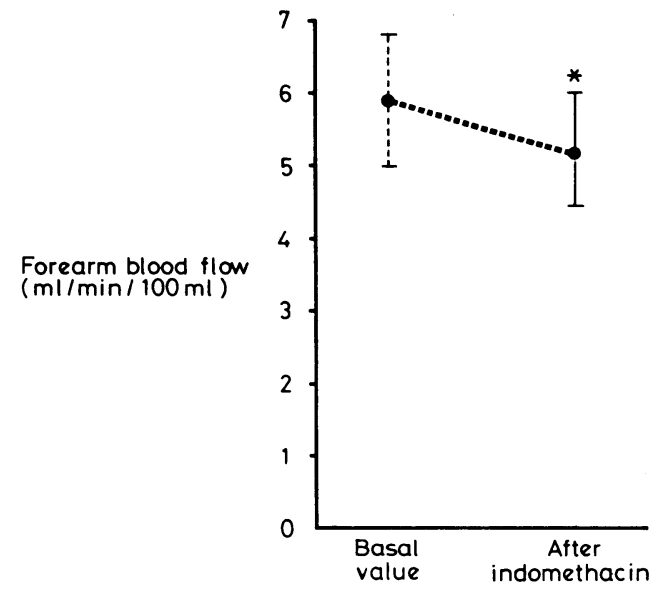

FIG 4-Forearm blood flow before and after infusion of $50 \mathrm{mg}$ indomethacin Compared with basal value: ${ }^{*} \mathrm{P}<0.02$.

\section{Discussion}

We found that indomethacin was highly effective against postural hypotension in patients with idiopathic Parkinsonism. The reduction of forearm blood flow and enhanced bloodpressure response to the cold pressor test suggest that given intravenously the drug causes vascular smooth-muscle constriction both in basal conditions and after neuroadrenergic stimuli.
We cannot explain the effect of indomethacin in raising the peripheral vascular resistance. The drug may, however, inhibit the synthesis of prostaglandins and related substances, some of which are potent vasodilators. ${ }^{6}{ }^{8}$ This hypothesis may be the case in Bartter's syndrome, in which the kidney produces excessive amounts of prostaglandins. ${ }^{9-11}$ Nevertheless, in normal people and conditions in which excessive synthesis of prostaglandins does not occur a different mechanism of action of indomethacin - that is, independent of prostaglandin metabolism-cannot be a priori excluded.

Correspondence should be addressed to: Professor G Abate, Via G Zaccherini Alvisi 8, 40138 Bologna, Italy.

\author{
References \\ ${ }^{1}$ Ibrahim, M M, Tarazi, R C, and Dustan, H P, American Heart fournal, \\ 1975, 90, 513. \\ ${ }^{2}$ Rajput, A H, and Rozdilsky, B, fournal of Neurology, Neurosurgery, and \\ Psychiatry, 1976, 39, 1092. \\ ${ }^{3}$ Shy, G M, and Drager, G A, Archives of Neurology, 1960, 2, 511. \\ 4 Bannister, R, Davies, B, and Sever, P, Lancet, 1978, 1, 1312. \\ ${ }^{5}$ Bannister, R, and Oppenheimer, D R, Brain, 1972, 95, 457. \\ ${ }^{6}$ Kochar, M S, and Itskovitz, H D, Lancet, 1978, 1, 1011. \\ 7 Barritt, D W, and Marshall, A J, British Heart fournal, 1977, 39, 825. \\ 8 Wennmalm, A, Clinical Science and Molecular Medicine, 1978, 54, 141. \\ ${ }^{9}$ Richards, C J, et al, Circulation, 1978, 58, 544. \\ 10 Norby, L, Mark, A L, and Kaloyanides, G J, Clinical Nephrology, 1976, \\ 6, 404. \\ 11 Gill, J R, jun, et al, American fournal of Medicine, 1976, 61, 43.
}

(Accepted 24 September 1979)

\title{
Oral contraceptives and fatal subarachnoid haemorrhage
}

\author{
WILLIAM H W INMAN
}

British Medical fournal, 1979, 2, 1468-1470

\section{Summary and conclusions}

A case-control study was conducted of the deaths from subarachnoid haemorrhage (SAH) in women aged 15-44 in England and Wales in 1976. There was a small excess of oral contraceptive use by the women who died from SAH compared with their generally healthy practicematched controls; this was not, however, statistically significant. Out of 134 women who died from SAH, 34 had a history of hypertension compared with only six of their controls. Renal disease and pre-eclamptic toxaemia were more commonly associated with hypertension in the dead women than in controls.

No change in the annual mortality from SAH has been observed in the past 20 years such as might have been expected if the risks were high. Although current or past use of oral contraceptives may have increased the blood pressure and risk of SAH in a few women, the most

Committee on Safety of Medicines, Finsbury Square House, London EC2A 1PP

WILLIAM H W INMAN, MRCP, FFCM, principal medical officer

important factor in determining this risk was hypertension. SAH should thus probably not be regarded as a serious cause for concern in healthy non-hypertensive women using oral contraceptives.

\section{Introduction}

In October 1977 an analysis in the study of oral contraceptives carried out by the Royal College of General Practitioners (RCGP) of deaths among women suggested that there might be a strong association between the use of the "pill" and fatal cerebrovascular disease. ${ }^{1}$ Ten women who had used the pill at any time during the eight years of the study had died compared with only three controls who had never used the pill, and, of these 10 deaths, nine were from subarachnoid haemorrhage (SAH) compared with none of the deaths in the controls. The mortality rates from SAH were estimated to be 9.3 and 15.9 / 100000 woman-years among current and ex-users of oral contraceptives respectively.

Since perhaps as many as one-third of all women of childbearing age were using oral contraceptives while a further onethird may have used them in the past it would have been expected that such a large risk would have been reflected in the national mortality statistics published by the Office of Population Censuses and Surveys (OPCS). No such increase in deaths was apparent, and it was therefore decided to conduct a further study of deaths from SAH in the female population of England and Wales. 